\title{
Possibilidades e limites do conceito de "mito político": aspectos genealógicos e operacionais da noção nos estudos de Comunicação ${ }^{1}$
}

\author{
Potency and limits of the concept of "political myth": genealogical and \\ operational aspects of the notion in Communications Studies
}

\section{Angela Cristina Salgueiro Marques}

Doutora em Comunicação Social pela UFMG e professora do Programa de Pós-Graduação da UFMG.

\section{Anita Gonçalves Hoffmann}

Mestre em Comunicação pela Faculdade Cásper Líbero.

\section{Luis Mauro Sá Martino}

Doutor em Ciências Sociais pela PUC-SP. Professor do Programa de Pós-Graduação em Comunicação da Faculdade Cásper Líbero.

\section{RESUIMO}

O que é um mito político? Embora a expressão seja relativamente corrente nos estudos de comunicação política, não parece ter sido problematizada com a mesma frequência. Este artigo delineia alguns aspectos da noção com vistas a compreender alguns de seus significados e usos na literatura atual sobre estudos políticos. 0 conceito, empregado como operador interpretativo e epistemológico, ainda demanda um maior tensionamento em termos de sua gênese e potencial hermenêutico. A partir de pesquisa bibliográfica, este texto sublinha três aspectos da ideia: (1) uma genealogia inicial do conceito, enfatizando a articulação entre "mito" e "política"; (2) a questão contemporânea do "mito" nos estudos

\footnotetext{
${ }^{1}$ Este trabalho integra projeto de pesquisa apoiado pelo CNPq e pela Capes.
} 
de comunicação política; e (3) as tensões entre mito e entretenimento em uma sociedade midiatizada. Esses argumentos são enquadrados nos debates sobre mídia e política.

PALAVRAS-CHAVE: Mito Político. Política. Comunicação. Midiatização.

\section{ABSTRACT}

What is a political myth? Although the expression has found a significant place in Political Communication Studies it has not been directly addressed very often. This paper outlines some aspects of the notion of "political myth" in order to understand its meanings and uses in current political studies literature. It seems that the notion, although often employed as an interpretative and epistemological concept, still needs clarification. Grounded on bibliographical research, this text underlines three main aspects of the idea: (1) a partial genealogy of the concept, stressing the articulation between "myth" and "politics"; (2) the contemporary issue of "myth" in current political communication studies; and (3) the tensions between myth and entertainment in a media-dominated society. These arguments are framed in debates on aesthetics, media and politics. KEYWORDS: Political Myth. Politics. Communication. Mediatization.

\section{RÉSUMÉ}

Qu'est-ce qu'un mythe politique? Bien que l'expression soit relativement courante dans les études sur la communication politique, elle ne semble pas avoir été problématisée à la même fréquence. Cet article présente certains aspects de la notion afin de comprendre certaines de ses significations et utilisations de la littérature actuelle sur les études politiques. Le concept, utilisé en tant qu'opérateur interprétatif et épistémologique, exige toujours une tension en termes de genèse et de potentiel herméneutique. À partir d'une recherche bibliographique, ce texte met l'accent sur trois aspects de l'idée: (1) une première généalogie du concept, mettant l'accent sur l'articulation entre "mythe" et "politique"; (2) la question contemporaine du "mythe" dans les études de communication politique ; et (3) les tensions entre mythe et divertissement dans une société médiatisée. Ces arguments sont présentés dans les débats sur les médias et la politique.

MOTS-CLÉS: Mythe politique. Politique Communication. Médiatisation.

\section{Introdução}

Escrevendo na década de 1970, Dan F. Hahn e Ruth M. Gonchar (1972) indicavam a proeminência da imagem e da narrativa em relação à discussão de propostas na tomada de decisão eleitoral. Sintomaticamente, os autores enunciavam a questão em termos de um "mito" político - embora não prosseguissem na discussão -, utilizando como metáfora 
o livro 1984, de George Orwell. Essa teorização chama a atenção para a presença, nas disputas democráticas contemporâneas, de algo consideravelmente mais antigo: a presença das narrativas míticas no âmbito da política.

Estudos diversos mostram a presença de uma mitologia política com ampla vitalidade, como sugerem estudos - e a enumeração aqui não tem pretensão de exaustividade - realizados por Ávila Neto (2012), Garcia (2018), Onge (2018), Zhang e Zhong (2016), Kranert (2018), Reid (2017) e Zglobiu (2017) em países de quatro continentes. Essas pesquisas sugerem não apenas uma expansão da utilização de narrativas míticas na política como também sua potencialidade nos estudos da área e mesmo em uma concepção mais ampla de política.

Para Rancière (2018), por exemplo, um relato mitológico, ao ordenar os acontecimentos de maneira causal, não consegue dar conta da "vida de verdade"; ele quer sinalizar que que uma narrativa como essa corre o risco de impossibilitar as descontinuidades dos laços temporais que costuram as experiências e as existências. Narrativas míticas, segundo ele, não apresentam lapsos, falhas, necessidades de reparo ou possibilidades de rupturas.

Para ele, uma narrativa mítica nos conduz de um ponto a outro, sem possibilitar momentos de desaceleração, contemplação ou desvios de rota: não há muita margem para suspeitar, suspender ou produzir intervalos de descanso e refazimento. De acordo com o autor, um relato que não segue a estrutura causal adotada na composição da narrativa mítica - uma espécie de contra-mito - se recusa a "jogar o jogo da conexão entre o que está previsto e o que acontece" (2018, p.84).

O que preocupa Rancière é a forma como a narrativa mítica constitui obstáculos para a capacidade de inventar e de alterar os enquadramentos através dos quais os acontecimentos são apreendidos e lidos. Ele sugere a necessidade de contrariar o encadeamento combinado de causas e efeitos, a previsibilidade, a relação entre o que estaria previsto e o que acontece.

Este artigo delineia alguns aspectos da noção com vistas a compreender alguns de seus significados e usos da literatura atual sobre estudos políticos. 0 conceito, empregado como elemento interpretativo e epistemológico, demanda maior tensionamento em 
termos de sua gênese e potencial hermenêutico em uma epistemologia da comunicação política, como indica Signates (2012). 0 texto se concentra em três dos vários aspectos relevantes da ideia: (1) uma genealogia inicial do conceito, enfatizando a articulação entre "mito" e "política"; (2) a questão contemporânea do "mito" nos estudos de comunicação política; e (3) as tensões entre mito e entretenimento em uma sociedade midiatizada. No que segue, o artigo desenvolve cada uma dessas perspectivas.

\section{0 mito político: pontuações de uma genealogia}

O conceito de mito político parece derivar, em sua origem, de certas concepções da antropologia política que, caudatária de estudos referentes aos aspectos do rito, das narrativas e práticas sociais, articula os dois conceitos - "mito", de um lado; "política", de outro - em uma formação conceitual com alto potencial heurístico. No entanto, em que pese essa possibilidade de operacionalização epistemológica do conceito, como parece atestar seu uso corrente na análise política, vale por outro lado colocar uma questão de origem: "mito" e "política", em suas concepções iniciais, referiam-se a elementos distintos, embora não desprovidos de entrelaçamentos.

De que maneira essas duas categorias dialogam? A partir de qual momento essas duas configurações conceituais, uma ligada à narrativa, outra às práticas de administração e tomadas de decisão, confluem para uma interpretação do fenômeno político contemporâneo? Finalmente, em que medida a natureza da política contemporânea, em uma sociedade marcada pelo processo de midiatização, encontra no conceito de "mito político" uma expressão articulada com as necessidades interpretativas do momento? Responder a esse conjunto de perguntas demanda um trabalho mais amplo, mas é possível delinear algumas dessas problemáticas.

Em sua concepção original, o mito na Grécia antiga tinha uma considerável força política como provedor de uma identidade de grupo, vínculo de comunidade criado a partir da referência a certa ancestralidade comum, responsável por garantir não apenas o sentido de ações passadas, mas justificar diferenças presentes. A inserção da narrativa mítica não se dava de maneira separada de uma história de origem, tanto mais 
referenciada quanto mais importante se tornasse nas práticas regulares da vida política (Goldschmidt, 1965; Vernant, 1974; Vernant; Naquet, 1989; Lesky, 1996).

Em uma cultura oral, marcada por um tempo que se estruturava em torno de um escrito incipiente mas ainda relacionado, em boa medida, a uma duração acronométrica da narrativa transmitida oralmente, o mito se estabelecia como um dos critérios para realçar os espaços de pertencimento. Pertencer a uma narrativa significava encontrar-se no espaço trazido, de maneira genealógica, ao sentido de um comum revestido de ingredientes mais amplos do que as preocupações cotidianas, atualizado nas relações horizontais com os demais (Vernant, 1998).

A uma cosmologia presente na narrativa mítica correspondia também uma antropologia política ligada aos processos de diferenciação social, legitimação de determinados grupos em detrimento de outros e a formação de um conjunto de práticas sociais reconhecidos por uma origem comum. 0 entrelaçamento da mitologia com o cotidiano se dava na forma de uma narrativa de origem constantemente atualizada nos rituais que perfazem a natureza de reavivamento periódico do mito - as práticas religiosas, de um lado, mas também as festas, celebrações e jogos, de outro.

A elaboração da narrativa mítica, em torno de feitos heroicos, geralmente é tomada como fundamento e referências dos quadros simbólicos de uma comunidade ou grupo social. Um mito articula elementos e feitos de caráter exemplar e que reiteram uma forma específica de legibilidade e inteligibilidade de acontecimentos concretos. Não raro, a narrativa que organiza grandes feitos históricos expressa pontos de vista e argumentos daqueles que, em determinado momento e tempo situado, possuem legitimidade para, a partir de um lugar de fala hierárquico e assimétrico, construir enquadramentos que serão amplamente disseminados e impostos como padrões de interpretação e julgamento. É dessa forma que uma narrativa mítica, e sua estrutura simbólica, fornecem modelos de conduta, conferindo significações e modelando os processos de construção de sentido (Morais, 1988).

Sob esse aspecto, uma narrativa mítica é um ato fundador: ela instaura personagens, características e formas de enquadrar e "ler" os acontecimentos que se transformam em matrizes quase que normativas de entendimento e apreensão sensível 
do "real". Se a função do mito é mesmo a de revelar modelos de conduta e de fornecer significados ao mundo e às formas de vida, é preciso nos indagarmos acerca de quais são os mitos que hoje conduzem e orientam nossos julgamentos e nossa postura em relação aos temas morais e de justiça que atravessam e organizam o "comum" que congrega um povo ou uma sociedade.

A reconstrução mítica do vivido tem uma função importante: produzir um "esquema que permite compor conjuntamente circunstâncias, intenções, motivos, encontros, adversidade, êxitos, fracassos, felicidade e infortúnio." (Morais, 1988, p.65). Contudo, a função fabuladora da experiência pode não necessariamente ser algo que propicia a emancipação dos sujeitos: pelo contrário, dependendo da forma como organizamos e produzimos arranjos que disponham e coloquem em contato nossas vulnerabilidades, fracassos e oportunidades de aprimoramento, podemos dificultar ou facilitar a construção de percursos marcados pela resistência e pela recusa.

Em termos políticos, o mito conferia uma unidade ou, mais ainda, um sentido de comunidade e pertencimento responsável por conferir certos parâmetros de ação "histórica" a partir de uma genealogia: o mito precede a história, Homero precede Heródoto, e à explicação factual do último não deixa de haver uma certa precedência da composição mitológica do primeiro.

E, vale notar, a indicação de Homero não é mais do que episódica, na medida em que, em sua marca de oralidade, o mito, assinala Vernant (1996), é consideravelmente anterior a qualquer registro escrito - o tempo mitológico se apresenta como um tempo "antes", "heróico", diferente do tempo ordinário da política existente em algum momento e que tende a ser constantemente rememorado como forma de celebração da própria identidade. Talvez não seja coincidência que, em sua Oração fúnebre, Péricles destaque os feitos dos atenienses oferecendo um quadro de suas qualidades frente ao momento em que estava.

O sentido vivo de um passado imaginário se atualizava no mito grego como expressão de uma força política responsável por garantir a unidade do presente em termos de uma comunidade - o demos, espaço de relativa igualdade reforçado por uma origem comum. Relacionando-se com a celebração periódica do trágico, sua política 
apresentava-se como uma continuidade, em termos identitários, do mito, vivido cotidianamente como substrato das práticas políticas.

Mas até um certo limite: se a perspectiva mitológica se apresenta como espaço de formação e sustentação do demos, a partir daí observa-se uma separação parcial das práticas entre o espaço do propriamente mítico ou religioso como garantia da unidade teológico-política da cidade - Sócrates foi condenado por introduzir "deuses estrangeiros" - e os momentos propriamente políticos, como as escolhas, deliberações e tomadas de decisões no espaço da Ágora.

Próxima dos templos, sem dúvida, mas distante o bastante para que as deliberações do demos não fossem sustentadas, ao menos em sua medida principal, por uma autoridade religiosa: a Grécia antiga parece ter sido um dos poucos regimes da antiguidade, senão o único antes da república romana, a não ter a necessidade de um reisacerdote ou rei-divindade como líder, mas sustentar-se em uma experiência de administração regida pelos próprios cidadãos.

A esfera da tomada de decisões, embora relacionada a esse aspecto mitológico em termos identitários, não se organizava em torno de práticas ou justificativas religiosas, mas dentro das regras e organizações da pólis: a remissão aos mitos de origem não chegava necessariamente ao âmbito da tomada de decisões - um cidadão não justificaria seu voto em nome dos deuses, mas de suas perspectivas representadas no espaço de tomada de decisões.

A escolha dos cargos e seus ocupantes resultava de um processo deliberativo comum, em que pese as inúmeras exclusões, nos quais o grande ausente era a personificação do mito político - se existia, era em termos da pólis, não desta ou daquela figura. Nem legisladores e administradores, como Sólon ou Péricles, ganham espaço dentro de uma estrutura mitológica.

Talvez seja sintomático que a divinização do mito político tenha acontecido fora do espaço de racionalidade democrática da Grécia antiga, e encontrado uma manifestação concreta quando os romanos proclamam Otávio César como "augusto", título honorífico inimaginável para seu tio Júlio, etimologicamente aparentado com "augmenta", "o que aumenta", entronizando o culto à divindade daquele que detém o domínio sobre um vasto 
território de reinos, o "imperator", designado também como o "primeiro cidadão", "princeps". "Princeps", "imperator", "Augustus": aos títulos políticos do cidadão que se destaca no comando do estado é acrescentado uma outra palavra que o alça a uma posição semidivina, elevado não apenas como membro da república, mas como alguém acima dela, responsável por sua proteção: está ligado ao povo, mas como sua personificação viva. Tal feito não pode ser alcançado por um mortal, sendo necessária portanto uma justificativa na ordem de uma teologia política: Augusto só pode ser divino.

Essa junção aparentemente simples, que não deixava de ser uma reedição elaborada das diversas teocracias da Antiguidade, conserva uma descendência conflituosa do conceito do soberano divino ressaltado como mito político em uma continuidade: "César", nome de família, torna-se um título, "césar", encontrando formas modernas como o alemão "kaiser" ou o russo "czar".

O imperador deve ser adorado como um ser divino: sua história se inscreve no âmbito do mitológico. No entanto, está também articulada a uma história: a personificação do soberano implica sua inscrição na temporalidade de sua vida, bem como na manutenção e sobrevivência de seu domínio. A persistência de uma ideia mitológica associada à política, em especial à liderança política, encontrará uma considerável descendência no período medieval, sobretudo a partir de características mostradas nos trabalhos clássicos de Marc Bloch (1996) e Kantorowitz (1998).

Em "Os reis taumaturgos", Bloch (1996) mostra os caminhos de criação e manutenção da crença no poder curador dos reis. Entendido como um intermediário entre Deus e seus súditos, a figura do rei estava muito distante da ideia contemporânea de uma "monarquia constitucional", como são, na atualidade, as monarquias britânica ou espanhola: a concepção corrente era de que o rei, nascido rei pela vontade de Deus, ungido rei pelo Papa - ou seu representante, o arcebispo local - era de natureza qualitativamente diferente de todas as outras pessoas, e, dessa maneira, portador de poderes sobrenaturais derivados de sua condição.

A cura de algumas doenças pelo "toque do rei", tema do estudo de Bloch, era um dos pontos mais visíveis dessa concepção divina do rei como uma pessoa de condição extraordinária. A crença no poder curador dos reis, mostra Bloch (1996), estende-se até 
o período moderno, e parece ter seu lugar na genealogia de uma mitologia política do líder como "curador" ou "salvador".

A mesma perspectiva extraordinária da condição semidivina do rei colocava, no entanto, um problema de ordem prática: como lidar com a humanidade do rei, com um corpo físico que tinha sido visto no nascimento, acompanhado ao longo da vida e, inequivocamente, dava sinais de envelhecimento e morte? Kantorowitz (1998) mostra a resolução desse problema a partir da ideia dos chamados "dois corpos" do rei: entidade político-metafísica representada a partir de símbolos, práticas e sinais, o "rei" encontrava sua corporificação momentânea no indivíduo ungido que recebia a coroa real - a frase "o rei morreu, viva o rei", em sua sucessão ininterrupta, é um indício dessa condição.

A permanência desse tipo de mentalidade, no dizer de Duby (2005), pode ser observada em alguns aspectos das práticas políticas contemporâneas, sobretudo no que diz respeito à persistência da ideia de uma condição especial da liderança política, revestida de poderes especiais ou condições extraordinárias de existência, sintetizadas na expressão "mito político". É o tema do próximo item.

\section{Tensionamentos empíricos nos estudos de comunicação política}

Nos estudos contemporâneos sobre mito político na comunicação, nota-se que o conceito está ligado muitas vezes à noção de espetacularização político-midiática, que se dá quando fatos e acontecimentos transformam-se em espetáculos seguindo as vontades e os interesses de atores tanto da política quanto da mídia (Weber, 2000). As figuras políticas mitificadas ganham força, portanto, por meio da visibilidade midiática, lugar onde conquistam credibilidade, opiniões e votos, ou seja, onde se legitimam.

É importante ressaltar que o conceito pode ter diversas interpretações, dependendo de onde é acionado, evocando ideias falsas e ilusões quando ligado ao campo semântico da mentira (Sauvy, 1971), ao sagrado ou ao profano quando se refere às narrativas míticas antigas, ou à "mistificação", termo abordado por Barthes (2013) como construção ideológica, roubo de linguagem, com a função específica de transformar um sentido em forma, e que encontra força, sobretudo, na esfera burguesa. 
Para Rancière (2018), a História é escrita sob a forma de uma narrativa mítica que "segue o princípio aristotélico de toda ficção: o de ter começo, meio e fim e dirigir-se do primeiro ao último elemento por um encadeamento combinado de causas e efeitos" (2018, p.80).

Soma-se a isso o fato de que a narrativa mítica não só organiza causalmente o real como também nos fornece uma chave de leitura desse real: passamos a ler o mundo através de uma lente quase que determinista, muitas vezes prevendo que algo vai acontecer, porque nosso olhar articula causalmente os fragmentos de acontecimentos e projeta uma expectativa diante de nós. A narrativa mítica é da ordem do esperado, daquilo que está previsto.

A narrativa mítica, em sua chave aristotélica, nos apresenta como questão a busca por "saber em que momento acontecerá o que sabemos que tem que acontecer, momento que a arte da narrativa retarda até o ponto em que a tensão chega ao clímax"(2018, p.82). 0 que Rancière nos apresenta é um questionamento acerca das possibilidades de entrelaçamento dos eventos que organizam a História e as histórias que dela fazem parte: não seria adequado valorizar somente como as coisas acontecem uma após a outra, em sua particularidade, mas destacar a importância dos momentos quaisquer, que não se encaixam no encadeamento específico de causas e efeitos que levam da felicidade à infelicidade e vice-versa.

0 mito, entendido como palavra sagrada e original, prende-se à valorização de um certo tipo de enunciação, expressão e organização do saber: "Verificamos que os princípios aristotélicos da racionalidade ficcional produzem hoje ainda a matriz estável do saber que nossas sociedades elaboram" (Rancière, 2017, p.8). Diante dessa palavra original legitimada, como construir um outro entendimento de mito que possa oferecer espaço para outras palavras e epistemes? Estamos de acordo com a afirmação de Fabri, segundo a qual uma palavra mítica "eficaz" não tem que ser necessariamente aquela construída em torno do lugar de fala das autoridades hierárquicas (sejam elas políticas, religiosas, sociais ou científicas), mas aquela que não silencia ou oprime as enunciações da alteridade:

A palavra do outro é também palavra eficaz, criadora de possibilidades, instauradora de mundos. Essa ausência do mítico seria, assim, suprida por uma

Dossiê A Música e suas Determinações Materiais - https://revistaecopos.eco.ufrj.br/ 
atitude de escuta, tanto de realidades próximas (populações carentes), como distantes (Oriente, sociedades primitivas). Para tanto urge indagar qual seria a palavra que teria força suficiente para nos colocar num gesto de comunhão e encontro (1988, p. 35).

Bezerra e Lima (2009) esclarecem que a elaboração de um mito acontece de forma mais constante a partir da contínua repetição e reelaboração de uma imagem, ou seja, por meio de uma narrativa, de uma sequência de uma história contada, repetida e reelaborada. Dessa forma, considera-se que, além de ser palco da instituição e fortalecimento dos processos de espetacularização, a mídia mostra-se como um ambiente propício para a propagação de discursos perpassados de elementos simbólicos e míticos, um local onde narrativas ganham força.

Talvez a primeira grande tentativa de construção de um conceito de mito político surgiu no início do século XX, na obra de Georges Sorel, marxista heterodoxo ligado ao sindicalismo revolucionário de extrema esquerda e envolvido por um tempo com a extrema direita monarquista. Sorel pensou o mito político em seu caráter revolucionário, como elemento irracional necessário para o êxito do movimento operário que, representando um instrumento de ação coletiva, era capaz de guiar o proletariado à revolução. Para ele, o mito é a força motriz para a incitação ao movimento operário, instrumento de ação política que se manifesta quando a razão não se apresenta. Caso o faça, o mito político torna-se passível de contestações e descrenças, e perde sua força.

Também nessa linha, Ernst Cassirer (1976), ao estudar as sociedades do século XVIII e XIX, identifica uma mudança radical nas formas do pensamento político-social, com a supremacia do pensamento mítico em relação ao pensamento científico. Para ele, o mito era um elemento pejorativo, oposto à ciência e à racionalidade, e alinhava-se à ideia de mentira e ficção. Quando relacionado à política, portanto, o mito seria uma ideia a ser combatida, pois poderia degradá-la.

Roland Barthes (2013) considera que mistificação se apresenta à razão procurando iludi-la, fazendo com que aceite como evidência natural o que é construção ideológica. "Natureza”, para ele, é o objeto ou o acontecimento por si mesmo, já história é a narração ou a forma como a natureza é apreendida. Ao tratar das mitologias contemporâneas, Barthes diz que o mito constitui uma fala despolitizada, que tem a 
função de transformar uma intenção histórica em natureza, uma eventualidade em eternidade. $\mathrm{O}$ mito, portanto, abole a complexidade dos atos humanos, confere-lhes a simplicidade das essências e suprime toda e qualquer dialética, organizando um mundo sem contradições onde as coisas sozinhas parecem significar por elas próprias.

0 que o mundo fornece ao mito é um real histórico, definido, por mais longe que se recue no tempo, pela maneira como os homens o produziram ou utilizaram; e o que o mito restitui é uma imagem natural desse real. E, do mesmo modo que a ideologia burguesa se define pela deserção do nome burguês, o mito é constituído pela eliminação da qualidade histórica das coisas; nele as coisas perdem a lembrança da sua produção. 0 mundo penetra na linguagem como uma relação dialética de atividades e atos humanos; sai do mito como um quadro harmonioso de essências (Barthes, 2013, p. 234).

No livro Mitos e Mitologias Políticas (1987), Raoul Girardet afirma que todas essas formulações parecem corresponder a alguns dos principais aspectos do mito político sem esgotá-lo ou abarcar seu conteúdo. Girardet trata o mito como um sistema de crença coerente e completo, reflexo de um sistema de valores ou de um tipo de mentalidade que pode surgir dos pontos mais diversos do horizonte político, classificando-se "à direita" e "à esquerda", segundo o momento (1987, p.12).

Girardet (1987) propõe que a criação de mitos políticos é enfatizada em momentos da história em que há inquietações políticas. Para chegar a essa constatação, ele considerou os dois últimos séculos da história europeia, que se fizeram acompanhar de uma considerável efervescência mitológica. Ao levar em conta a relação intrínseca entre o mito e o contexto histórico, faz-se necessário ter em mente que os elementos míticos são hoje veiculados nos discursos políticos e publicizados através da imprensa, que serve como terreno propício para o surgimento de personagens míticos de diferentes classes, ideologias, propostas e discursos.

Entre os estudos sobre mito político no Brasil, destacam-se as contribuições de Luís Felipe Miguel (1998), que no livro Mito e discurso político, fruto de sua tese de doutorado, analisa os elementos míticos presentes nos discursos dos candidatos à presidência da República das propagandas veiculadas na televisão na eleição de 1994 . Miguel parte do pressuposto de que o conceito de mito político é, muitas vezes, usado de forma frouxa e superficial, e apresenta exemplos que sustentam a relevância e pertinência

Dossiê A Música e suas Determinações Materiais - https://revistaecopos.eco.ufrj.br/ 
para a análise de discursos políticos, mostrando, também, as alterações que os meios de comunicação de massa impõem a esses discursos. Ele afirma que, na mídia, ao invés do mito ser abordado como uma narrativa, como nas sociedades primitivas, há o flash mítico, a imagem instantânea que dialoga com o imaginário social preexistente. Além disso, busca compreender os mecanismos que levam os cidadãos comuns a aderirem a partidos, movimentos e personalidades políticas, e discute sobre como o imaginário coletivo impõe limites à eficiência do mito, ao mesmo tempo que serve como um manancial onde ele bebe.

Miguel discorre sobre a consonância que existe entre a ideia de uma democracia representativa, onde os eleitores são conscientes e tomam decisões baseados em informações que visam ao bem comum, e a realidade existente na hora do voto, já que os eleitores nem sempre agem de acordo com seus interesses racionais e se deixam levar por hábitos, valores simbólicos e ligações emocionais.

Em sua análise das eleições de 1994, ele identifica que o candidato Enéas Carneiro, do extinto partido Prona, é a figura que mais se aproxima do mito político clássico do Salvador da Pátria, e afirma também que, apesar de não se configurarem plenamente dentro da categoria clássica de mitos políticos, os outros candidatos também têm características míticas em suas narrativas. O louvor à unidade é identificado nos discursos de Fernando Henrique Cardoso (PSDB), que acabou vencendo a eleição, e Orestes Quércia (PMDB). Segundo o autor, embora haja diferença de qualidade, o mito da autoridade presidencial pertence à "mesma família" do mito do Salvador da Pátria, pois nele a unidade da nação aparece encarnada em uma pessoa que é a um só tempo sua representação e sua garantia.

Sinais do mito da unidade foram identificados na campanha de Fernando Henrique Cardoso, que assumiu o papel de pacificador graças à campanha do Plano Real, que lhe deu legitimidade para falar pela totalidade do corpo social como um herói antiinflacionário. Já Luiz Inácio Lula da Silva, que disputava sua segunda eleição presidencial na época, recorreu à narrativa da vivência, à sua história de vida, para disputar o discurso da competência por meio da ideia da transparência e da denúncia à máquina do Estado.

A trajetória política de Lula, que em 2002 tornou-se presidente do Brasil, foi inspiração para outros estudos sobre mitologia política. Bezerra (2009) dedicou-se à 
análise da construção da imagem pública de Luiz Inácio Lula da Silva a partir do acionamento de elementos simbólicos e míticos, tendo como palco de atuação desta imagem o cenário midiático, em especial a mídia impressa e eletrônica. Passos (2017) também considerou a trajetória de Lula como objeto de estudo; no entanto, analisou como sua imagem política foi desconstruída no contexto da crise política de 2016, que culminou no impeachment da presidenta Dilma Rousseff, e como foram acionadas as narrativas do mito político nesse processo, especialmente no Twitter.

Além disso, a pesquisadora identificou também nas conversações do Twitter sobre Lula a figura do Salvador da Pátria. Enquanto seus apoiadores o consideravam o guerreiro do povo brasileiro, alguém que deveria ser protegido das tentativas de destruição de sua imagem, seus opositores decretavam o fim do "herói Lula". Por fim, Passos concluiu que a grande mídia, presente no Twitter com perfis profissionais, foi uma das principais responsáveis pela desconstrução da imagem de Lula.

Por seu turno, Ana Margarida Parreira (2013) estudou o mito como um instrumento de persuasão dentro da propaganda política. Em sua pesquisa, conclui que o mito político se revela na promoção de um caminho político único e inevitável, desvalorizando toda e qualquer alternativa; ela explica que, nesse tipo de comunicação, a solução política difundida pelo governo reveste-se de um caráter de predestinação que a leva a se ser aceita enquanto natureza. Ela identificou, ainda, que a criação de uma ideia de unanimidade e o apelo ao consenso social e à responsabilidade política também foram fatores presentes na comunicação do Primeiro-Ministro, com a exaltação do empreendimento de esforços e sacrifícios para um bem comum, que seria a criação de uma nova realidade política e social, um ambiente em favor de um consenso ditado pela emergência nacional, já que o país passava por um momento de dúvidas, incertezas e angústias quanto ao futuro.

Após essa apresentação de exemplos de aplicação do conceito de mito político nos estudos contemporâneos de comunicação política, no próximo item trataremos das tensões entre mito e entretenimento sob a perspectiva da midiatização. 
Tensões do mito com o entretenimento e a política

Uma terceira característica da perspectiva de mito político parece encontrar um espaço privilegiado nas narrativas vinculadas a uma dramaturgia política presente nas relações de comunicação, que, próxima da narrativa mítica, se vincula sobretudo às formas contemporâneas do entretenimento midiático, recorda Panke (2010). Se, como afirma Barthes (2013), o mito pode ser entendido como uma "fala" ou narrativa, talvez não seja de todo errado considerar que a apropriação dos temários políticos no âmbito da mídia se liga às formas de representação já consagradas pelo cinema, rádio, televisão e das mídias digitais.

Enquanto categoria de análise nos estudos de política, a noção de mitologia parece esbarrar em um condicionante específico, também já apontado por Barthes (2013) mas não plenamente desenvolvido, ao que parece, como maneira específica de se lidar com as questões referentes à mitologia contemporânea: a presença do mito retomado como signo dos elementos de uma cultura midiática definida, entre outros fatores, pela presença significativa do entretenimento. É possível ver aí um movimento de tensionamentos e articulações entre as potencialidades da formação de mitos no ambiente midiático contemporâneo, de um lado, e das propriedades específicas da articulação política, de outro, no sentido dos termos em que Meyer (2002) entende como a "colonização" da política pela mídia.

O termo designa, para Meyer, a adaptação de elementos do campo político para se adequarem ao que define como "lógicas da mídia". Na medida em que a legitimidade de um sistema político democrático está ligada à definição popular, sobretudo pelo voto, a visibilidade no espaço público torna-se uma necessidade constante para o campo político para a definição de uma "opinião pública”, sobretudo em épocas eleitorais, o que encontra eco em Thompson (1995).

O significado dessa presença da política na mídia depende, na visão de Meyer, não apenas de movimentos do campo dos meios, em particular do campo do jornalismo, da publicidade e das relações públicas, no sentido de articular uma "cobertura política" ou "propaganda política”, mas uma movimentação parcial do campo político para se adequar 
às rotinas, linguagens e características específicas das mídias - a "lógica da mídia”. Lundell (2010), a título de exemplo, mostra como a imagem pública de políticos é cuidadosamente criada para, ao mesmo tempo, se adequar e resistir às demandas da visibilidade midiática.

Esse tensionamento proposto por Meyer leva imediatamente à possibilidade de se indagar quais são, efetivamente, essas “lógicas da mídia”, sobretudo dentro de um cenário de midiatização da sociedade: um dos pontos levantados, entre outros, por Van Zoonen (2006), Street (2000) ou Riutort (2007) é o fato dessa intersecção passar, nos espaços da mídia, pela profissionalização e pelo entretenimento, em uma produção midiática de alta abrangência.

Alguns aspectos da mitologia política moderna parecem estar ligados à intersecção com características da mídia - e talvez fosse possível falar, seguindo Meyer, não apenas de uma "lógica da mídia", mas de uma "lógica do entretenimento", que se configura, como recordam Brants e Neijens (1998), Brants (2008), Dejavite (2007) e Martino e Lobato (2011) como gênero híbrido de informação e entretenimento. Os formatos da mídia, sobretudo importados do cinema, programas jornalísticos e teledramaturgia, articulamse com conteúdos políticos, formando o que poderia eventualmente ser entendido quase como um paradoxo entre a seriedade esperada e suposta das temáticas políticas e a leveza do entretenimento - sobretudo quando se pensa em termos de dramaturgia e mito como narrativa, e recorre-se novamente a Barthes (2013).

Não por acaso, a presença das mitologias políticas não ocorre necessariamente nos espaços do jornalismo - caracterizado, dentro de sua lógica de campo, por uma perspectiva de seriedade, recordam Gomes (2009), Guerra (2009) e Benedeti (2009) -, mas nas variadas formas do entretenimento, do uso de redes sociais no sentido de fomentar ou repercutir informações de relevância política pequena, mas de alta repercussão na própria mídia por seu interesse como "curiosidade" - Barthes (1998) refere-se a isso como o "fait divers" - até o emprego de recursos do cinema ou da teledramaturgia em campanhas eleitorais, como identifica Ferrari (2001) .

Seria possível pensar, nesse sentido, quase em uma tensão - palavra forte, mas talvez não menos necessária para caracterizar a situação - dos aspectos do mito político diante do entretenimento, quando a força específica da narrativa mítica encontra um 
espaço de divulgação necessário para a própria sobrevivência do campo político, ao mesmo tempo em que, articulada com essa "lógica", amplia de maneira indefinida e imprevisível aspectos singulares da política que acentuam a diferença apontada por Albuquerque (2004) entre "política partidária" e "política midiática": o candidato tornase maior do que seu partido, o discurso sem proposições políticas no sentido estrito passa a ser mais importante do que as propostas de ação, o recurso retórico se sobrepõe à possibilidade de uma perspectiva dialógica.

Nesse aspecto, o mito político relaciona-se, em uma articulação tensional, não apenas com o ambiente da mídia, mas também com o próprio campo político, no sentido de, a partir de uma visibilidade midiática ampliada, ter algum peso - não determinante nas próprias tomadas de posição (mas não de decisões) de seus agentes. 0 mito político atua, dessa maneira, para além de qualquer imagem, tornando-se um polo de interações e atrações dentro da prática política.

É possível questionar em que medida a noção de uma "mitologia política" se transforma em sua apropriação pela mídia dentro de uma lógica de entretenimento no qual o sentido da visibilidade política - sempre parcialmente, é importante ressaltar - se mistura com toda a "mitologia cotidiana" estudada por Barthes (2013) ou, sobretudo e ainda com mais força, por Morin (1989; 2003). Dentro de sua divulgação midiática, o mito político parece se revestir de características que o impelem a uma ampliação de seu escopo até tornar-se, em alguns casos, indiscernível em relação ao sucesso das celebridades e figuras de destaque na mídia.

Talvez não seja coincidência que Van Zoonen (2004) indique uma dimensão dramatúrgica da política contemporânea que a aproxima mais dos modelos consagrados de representação dramática da ficção contemporânea do que propriamente do debate sobre assuntos públicos: uma política baseada em lances dramáticos, declarações de ampla repercussão mas efeito mínimo para além de sua própria ressonância, atitudes e falas ecoadas principalmente no ambiente das mídias digitais mas distantes de uma real ação política (que, efetivamente, se desenvolve igualmente fora dos holofotes e das amplificações midiáticas). Sua contrapartida é o que Santos (2016) identifica como uma lógica de "fãs" do mito político, em uma forma nova e específica de engajamento. 
A articulação do mito político com o entretenimento parece ao mesmo tempo realçar e enfraquecer sua condição. Realça no sentido de aumentar a visibilidade de determinados posicionamentos e formas de atuação, ao mesmo tempo em que pode eventualmente também fragilizar a própria concepção da figura mitificada ao submetê-la à exposição intensa dentro de um cenário no qual a ideia de participação não se dá apenas, como esperado em algum momento, a partir de uma discussão política - Nazzari et alli (2007) já problematizavam essa perspectiva -, mas do juízo de valor e do julgamento moral apressado.

Na velocidade da mídia, o mito político ganha em visibilidade, mas parece perder - justamente por isso - uma de suas condições fundamentais: a ideia de distância entre o mito e o cotidiano, ressaltada desde sua origem grega, como sugerido no início do trabalho, em uma aproximação do que Meijer (2007) identifica como o "paradoxo da popularidade" no âmbito de um estudo sobre o que é considerado "real" no âmbito da recepção do jornalismo.

Nesse aspecto, o mito político se coloca, talvez de maneira um pouco contraditória, à margem do que se entende como um discurso político cotidiano, posicionando-se de maneira a estar ao mesmo tempo dentro e fora do campo político, conforme o ângulo em que se apresenta. Caroline Ávila (2012, p. 143) indica uma relação entre o crescimento do mito político e a rejeição da política tradicional: "quienes no tienen interés en política encontrarán en el mito una forma de apropiarse de conceptos y proyectos políticos de una manera más sutil, siempre y cuando se sientan parte del grupo al que va dirigido el mensaje".

A presença ostensiva de um deus absconditus, a "divindade escondida" da mitologia, na mídia, retira sua principal condição: justamente estar "escondido" e dosar sua visilibidade para manter-se dentro de uma faixa de ação para além da condição de trivialidade e se localizar em um outro espaço, o local do mito. 


\section{Considerações finais}

Escrevendo sobre a presença do mito político nas eleições equatorianas, Caroline Ávila (2012, p. 143) argumenta que "la aplicación del mito en la politica explica las circunstancias de vida del grupo de personas a quien se dirige, los ayuda a entender y proyectarse, les permite ver - como en un drama en curso - la condición en el presente y las futuras consecuencias o satisfacciones". É possível, portanto, indicar que o caminho de compreensão do conceito de mito político deve não apenas levar em conta a empiria contemporânea, mas observar que ele está ligado a um conjunto consideravelmente mais antigo de práticas políticas. Como complementa Zglobiu (2017, p. 116), "mitos políticos permitem moldar narrativas dos eventos em um cenário dramático".

A noção de "mito político", altamente polissêmica, define-se aqui em três aspectos: na sua origem grega, em termos do quadro maior de uma mitologia do povo, da nação e do estado; em sua possibilidade de operacionalização analítica; e em seu tensionamento com o entretenimento. Em que pese a diferença dos três aspectos, pode-se encontrar um ponto de unidade dentro da questão do mito como narrativa voltada para um exterior, no tempo e no espaço, a partir do qual se pode, em termos idealizados e talvez irreais, emitir julgamentos ou formular modos de ação política. Jeff Onge (2015, p. 350), em termos de uma síntese, indica que os mitos "são fundamentais porque fornecem uma compreensão das origens de um povo e são produtivos porque guiam os procedimentos de uma cultura para o futuro e estão continuamente abertos à mudança".

Como argumenta Cassirer (1972), o mito é uma narrativa, uma palavra que interpreta o vivido, reconstruindo o sentido de nosso ser no mundo e nossa forma de habitá-lo. Contar, fabricar intrigas e definir metáforas para a existência é produzir esquemas inteligíveis que nos auxiliam a ler e a nos inserirmos em uma trama que é composta pela articulação de circunstâncias, situações, intenções, adversidades, infortúnios, fracassos, êxitos e felicidade. A questão é quem produz e como produz essas intrigas, controlando todo o processo fabulador e inventivo que produz uma história sintética na qual cada coisa e cada indivíduo deve encontrar seu lugar e sua função. 
O problema então, como nos mostra Rancière, é a forma como as matrizes míticas de organização do real conseguem apagar a potência dos momentos e das formas de vida que oscilam "entre a reprodução do mesmo e a possível emergência do novo, que é também um momento pleno no qual uma vida inteira se condensa, onde várias temporalidades se misturam e onde a ficção fabrica outras maneiras de identificar os acontecimentos e os atores e outras formas de articulá-los para cosntruir mundos comuns e histórias comuns" (2017, p.13).

A produção de relatos contra-míticos teria a função de não permitir a diluição dos acontecimentos insignificantes da existência cotidiana - ou a brutalidade de um real - em narrativas totalizantes que insistem em incluir e reduzir a multiplicidade. Tal forma insurgente de ordenar o real recusa o encadeamento articulado e racional de ações (ou a racionalidade dos encadeamentos) presente na noção aristotélica de ficção (Rancière, 2017, p. 149).

Podemos pensar então na questão apresentada por Fabri (1988): qual seria hoje a palavra mítica capaz de construir os vínculos e laços do comum? Uma vez que as grandes narrativas não mais têm força para organizar nosso ser no mundo, não seria então hora de colocar em prática uma escuta atenta à palavra do outro, da alteridade radical que quase sempre é silenciada nos discursos oficiais?

Uma palavra mítica derivada do encontro com o outro traz de volta a humanidade inventada e preservada nos tempos singulares e que não se relacionam com a organização tradicional do tempo, que faz desaparecer cada momento dentro do seguinte, separando também "aqueles que viviam no mundo da ação daqueles que viviam no inframundo da repetição" (Rancière, 2017, p. 153). 0 tempo da palavra mítica no qual o encontro com o outro é possível torna evidente a falta de controle, a fugacidade e a instabilidade de uma dimensão política que o entendimento não alcança, não consegue justificar e nem legitimar por meio de regras apriorísticas. Tal dimensão política aparece quando dissociamos coisas e eventos que parecem indissociáveis, tornando sinuosos os arranjos que não possuem nenhuma lógica inerente de movimento e definição.

0 mito, nesse sentido, encontra também contranarrativas, espaços de dissenso, contra-mitologias que procuram se afirmar em disputas políticas que não deixam de ser 
disputas narrativas ou discursivas em torno da afirmação de significados específicos - e negação ou deslegitimação de outros.

A ideia de "mito", se remete a algo imemorial, situado fora de um tempo, no momento em que se torna o "mito político" empiricamente situado, encontra sua inscrição na história do presente e, portanto, passa a ser dotado de uma paradoxal temporalidade. Com isso, é possível situá-lo novamente dentro de uma cronologia e uma territorialidade, permitindo, nesse caso, seu questionamento e a produção de outras genealogias, narrativas e possibilidades de resistência e transformação.

\section{Referências bibliográficas}

ÁVILA NIETO, C. "El mito como elemento estratégico de comunicación política". Cuadernos de Información, no 31, Dezembro 2012, p. 139-150.

BARTHES, R. Mitologias. Rio de Janeiro: DIFEL, 2013.

BENEDETI, C. A. A qualidade da informação jornalística. Florianópolis: Insular, 2009.

BEZERRA, A. K. G.; Lima, E. C. de A. "A produção de mitos na política”. Biblioteca On-line de Ciências da Comunicação, v. 21, p. 01-30, 2009.

BLOCH, M. Os Reis Taumaturgos. São Paulo: Companhia das Letras, 1996.

BRANTS, K.; NEIJENS, P. “The infotainment of politics”. Political Communication, no. 15, v. 1, 1998, p. 149-164.

CASSIRER, E. $O$ mito do Estado. São Paulo: Códex, 2003.

CASSIRER. E. Linguagem e mito. São Paulo: Perspectiva, 1972.

FABRI, M. “A presença dos deuses”. In: Morais, R. de (org.). As razões do mito. Campinas: Papirus, 1988, p.31-35.

FERRARI, M. I. M. "O melodrama como olhar interpretativo das campanhas eleitorais na TV." Trabalho apresentado no IV Compolítica. UERJ: Anais... Rio de Janeiro, 13 a 15 de abril de 2011.

GARCIA, C. "The Power of Myths and Storytelling in Nation Building". Canadian Journal of Communication, v. 43, no. 1, 2018, p.281-296.

GIRARDET, R. Mitos e mitologias políticas. São Paulo: Cia. das Letras. 1987.

GOLDSCHIMIDT, V. A religião de Platão. São Paulo: Difel, 1963.

GOMES, W. Jornalismo, fatos e interesses. Florianópolis: Insular, 2009.

GUERRA, J. O percurso interpretativo na produção da notícia. Aracaju: Ed. da UFS, 2008.

HAHN, D. F.; Gonchar, R. M. "Political Myth: the image and the issue". Today's Speech, Verão de 1972, p. 57-65.

Dossiê A Música e suas Determinações Materiais - https://revistaecopos.eco.ufrj.br/

ISSN 2175-8689 - v. 23, n. 1,2020

DOI: 10.29146/eco-pos.v23i1.27550 
KANTOROWICZ, E. H. Os dois corpos do rei. São Paulo: Cia. das Letras, 1996.

KRANERT, M. "Political myth as a legitimation strategy". Journal of Language and Politics, v. 17, n.6, 2018, p.882-906.

LESKY, A. A Tragédia Grega. São Paulo: Perspectiva, 1996.

LUNDELL, A. K. "The fragility of visuals: How politicians manage their mediated visibility in the press". Journal of Language and Politics, v. 9, no. 2, 2010, p.219-236.

MEIJER, I. C. “The paradox of popularity”. Journalism Studies, v. 8, no. 1, 2006, p. 96 -116

MIGUEL, L. F. “Em Torno do Conceito de Mito Político”. Dados, v. 41, n.3, 1998.

MIGUEL, L. F. Mito e discurso político. Campinas: Unicamp; 2000.

MORIN, E. Cultura de Massas no Século XX. Rio de Janeiro: Forense, 1989.

MORIN, E. Sociologia. Lisboa: Europa-América, 2003.

NAZZARI, R. K. et alli. "Democracia virtual e capital social: internet e comportamento político". Ciências Sociais em Perspectiva, v. 6, no. 11, 2o. sem. 2007, p. 77-92.

ONGE, J. S. "Health Care Reform as 'Socialized Medicine': The Formative Years of a Political Myth". Western Journal of Communication, v. 79, no. 3, Maio-Junho 2015, p. 348-366.

PANAGIA, D. Rancière's sentiments. London: Duke University Press, 2018.

PANKE, L. "Política e entretenimento: cruzamento e/ou interferência na construção de sentidos". Animus, v. 18, n.1, 2010, p. 13-30.

PARREIRA, A. M M. 0 mito na comunicação política moderna: um estudo de caso. Dissertação (Mestrado em Ciências Sociais) apresentada na Universidade de Lisboa. Lisboa, 2013.

PASSOS, M. R. Mito e narrativa. Tese (Doutorado em Ciências da Comunicação) apresentada na ECA-USP. São Paulo, 2017.

RANCIERE, J. Les bords de la fiction. Paris : Éditions du Seuil, 2017.

RANCIÈRE, J. “O desmedido momento”. Serrote, n.28, 2018, p.77-97.

REID, J. "Political Myth-making in media policy". Journal of African Media Studies, v. 9, no. 3, 2017, p. 521-546.

RIUTORT, P. Sociologie de la communication politique. Paris: La Découverte, 2007.

SANTOS JR., M. A. "Coxinhas e petralhas: o fandom político como chave de análise da audiência criativa nas mídias sociais". Geminis, ano 7, no. 1, 2016, p. 117-146.

SAUVY, A. Mythologies de Notre Temps. Paris : Payot, 1965.

SOREL, G. Reflexões sobre a violência. São Paulo: Martins Fontes, 1992.

STREET, J. "Aesthetics, policy and the politics of popular culture". European journal of cultural studies, v. 5, no. 1, 2000, p. 27-45.

VERNANT, J-P. As origens do pensamento grego. São Paulo: Difel, 1974.

VERNANT, J-P. ; Naquet, P-V. Mito e sociedade na Grécia Antiga. São Paulo: Brasiliense, 1988.

WEBER, M. H. Comunicação e Espetáculos da Política. Porto Alegre: Ed. UFGRS, 2000.

ZGLOBIU, O. R. "Key Aspects of Myths and Metaphors in Romanian Political Discourse from a

Dossiê A Música e suas Determinações Materiais - https://revistaecopos.eco.ufrj.br/

ISSN 2175-8689 - v. 23, n. 1, 2020

DOI: 10.29146/eco-pos.v23i1.27550 
Cognitive Linguistic Perspective". Journal of Media Research, v. 10, no.3, 2017, p. 114-121.

ZHONG, L.; ZHANG, J. "Political Myth as Strategic Communication: Analysis of Chinese Dream's Rhetoric and English News Media's Interpretation". International Journal of Strategic Communication, v. 10, no. 1, 2016, p. 51-68. 